\section{Which spirometric indices best predict subsequent death from chronic obstructive pulmonary disease?}

Margaret J Thomason, David P Strachan

\begin{abstract}
Background-Previous epidemiological studies have related mortality from chronic obstructive pulmonary disease (COPD) to forced expiratory volumes $\left(\mathrm{FEV}_{1}\right.$ or $\left.\mathrm{FEV}_{0.75}\right)$ and it is unknown whether other spirometric indices might have greater predictive power.

Methods-A case-control study of fatal COPD was conducted within a cohort of London civil servants who performed forced expiratory spirograms in 1967-9 and were followed up for mortality over 20 years. The spirograms of 143 men who died of COPD (ICD8 491, 492 or 519.8) were compared with those of 143 controls individually matched for age, height, and smoking habit who survived longer than their matched case. Flow rates in different parts of the spirogram were compared within case-control pairs and analysed as predictors of fatal COPD by conditional logistic regression.
\end{abstract}

Results-Within pair case:control ratios of $\mathrm{FEV}_{1}$, mid expiratory flow rates (e.g. $\mathbf{F E F}_{50-75}$ ) and $\mathbf{F E F}_{75-85}$ were highly intercorrelated $(r>0.7)$ but correlations with FEF $_{85-95}$ were weaker $(r<0.5)$. All indices except the $F E V_{1} / F V C$ ratio were stronger predictors of death from COPD within the first 10 years than of later deaths (15-19 years). After adjustment for $\mathrm{FEV}_{1}$, mid expiratory flow rates independently predicted fatal COPD but end expiratory flow rates did not. The $\mathrm{FEV}_{1}$ adjusted mortality ratios associated with a $10 \%$ decrement in each index were 2.24 (95\% CI 1.54 to 3.76 ) for $\mathrm{FEF}_{50-75}, 1.20(95 \% \mathrm{CI} 1.00$ to 1.42$)$ for $\mathrm{FEF}_{75-85}$, and $1.10(95 \% \mathrm{CI} 0.96$ to 1.26$)$ for FEF $_{85-95}$.

Conclusion-This study confirms FEV $_{1}$ and mid expiratory flow rates as powerful predictors of mortality from COPD, and suggests that measurement of end expiratory flow rates would add little extra predictive information.

(Thorax 2000;55:785-788)

Keywords: chronic obstructive pulmonary disease; forced expiratory spirometry; mortality; predictors

The risk of death from chronic bronchitis, emphysema, or chronic airways obstruction (collectively termed chronic obstructive pulmonary disease, COPD) is closely related to the degree of impairment of ventilatory function. The latter is generally measured by forced expiratory volume in one second $\left(\mathrm{FEV}_{1}\right)$ or $\mathrm{FEV}_{0.75}{ }^{1-4}$ Reductions in these spirometric indices primarily reflect obstruction in the larger and medium sized airways, and may be a poor indicator of small airways dysfunction which has been proposed as an early stage in the natural history of COPD.

Most tests of small airways function require specialised lung function laboratory facilities and are therefore of limited value for epidemiological studies. ${ }^{67}$ Many large prospective studies have measured ventilatory function by forced expiratory spirograms and these results have usually been presented in terms of $\mathrm{FEV}_{1}$ and forced vital capacity (FVC). Reduction in end expiratory flow rates (when $75 \%$ or more of the FVC has been expired) may reflect small airways dysfunction which is not apparent from measurement of $\mathrm{FEV}_{1}$ or FVC. ${ }^{8}$

If the smaller airways are affected early in the natural history of COPD, then end expiratory flow rates might be a more powerful predictor than $\mathrm{FEV}_{1}$ of subsequent death from COPD, particularly for deaths occurring a long time after spirometric assessment. To our knowledge, there has been no study comparing different spirometric indices as predictors of COPD mortality in a population sample. We have therefore investigated these relationships in London civil servants who were followed for up to 20 years from the date of their spirometric assessment.

\section{Methods}

The Whitehall study examined 19018 male civil servants during 1967-9 as part of an occupational screening programme for cardiorespiratory disease and diabetes. ${ }^{9}$ The subjects were traced on the National Health Service Central Register and all subsequent deaths were notified and coded to the eighth revision of the International Classification of Diseases (ICD8). Chronic airways obstruction was identified by ICD 8 code 519.8 , introduced in 1978.

The baseline examination included a detailed smoking history and measurement of standing height. Three forced expiratory spirograms were recorded using a Vitalograph bellows spirometer. Measures of $\mathrm{FEV}_{1}$ obtained from these spirograms have been shown to predict mortality from chronic bronchitis, ${ }^{5}$ respiratory and cardiovascular disease, ${ }^{10}{ }^{11}$ and total mortality in lifelong non-smokers. ${ }^{12}$

This investigation was designed as a casecontrol study "nested" within the larger cohort. The case group were all men who died 
Table 1 Characteristics of cases included in the analysis by survival interval

\begin{tabular}{|c|c|c|c|c|}
\hline & \multicolumn{4}{|c|}{ Years from spirometric testing to death } \\
\hline & $<10$ & $10-14$ & $15-19$ & Total (\%) \\
\hline No of cases matched to control with spirogram & 48 & 50 & 45 & $143(100 \%)$ \\
\hline \multicolumn{5}{|l|}{ Age at entry (years) } \\
\hline $40-44$ & 1 & 1 & 0 & $2(1 \%)$ \\
\hline $45-49$ & 2 & 5 & 4 & $11(8 \%)$ \\
\hline $50-54$ & 2 & 6 & 9 & $17(12 \%)$ \\
\hline $55-59$ & 14 & 13 & 13 & $40(28 \%)$ \\
\hline $60-64$ & 15 & 20 & 13 & $48(34 \%)$ \\
\hline $65-69$ & 11 & 2 & 6 & $19(13 \%)$ \\
\hline $70-74$ & 3 & 3 & 0 & $6(4 \%)$ \\
\hline \multicolumn{5}{|l|}{ Smoking at entry } \\
\hline Never smoked & 3 & 0 & 2 & $5(4 \%)$ \\
\hline Former smoker & 10 & 13 & 14 & $37(26 \%)$ \\
\hline Pipe or cigar & 0 & 0 & 1 & $1(1 \%)$ \\
\hline Cigarettes $<20 /$ day & 11 & 16 & 16 & $43(30 \%)$ \\
\hline Cigarettes 20/day & 10 & 5 & 2 & $17(12 \%)$ \\
\hline Cigarettes $>20 /$ day & 8 & 10 & 7 & $25(17 \%)$ \\
\hline Hand rolled cigarettes & 5 & 6 & 3 & $14(10 \%)$ \\
\hline \multicolumn{5}{|l|}{ Coded underlying cause of death } \\
\hline Chronic bronchitis (ICD8 491) & 41 & 33 & 13 & $87(61 \%)$ \\
\hline Emphysema (ICD8 492) & 6 & 5 & 6 & $17(12 \%)$ \\
\hline \multicolumn{5}{|l|}{ Chronic airways obstruction } \\
\hline (ICD8 519.8) & 1 & 12 & 26 & $39(27 \%)$ \\
\hline
\end{tabular}

of COPD during 20 years of follow up. This included deaths from chronic bronchitis (ICD8 code 491), emphysema (ICD8 code 492), asthma (ICD8 code 493), or chronic airways obstruction (ICD8 code 519.8). There were no deaths coded as bronchitis unspecified (ICD8 490) or asthma (ICD8 493). For each case an individually matched control was selected as a man of the same age at entry (in single years), height (to the nearest half inch), and smoking habit (never, former, current pipe or cigar, current hand rolled cigarettes, and current manufactured cigarette smokers, divided into six categories according to amount smoked and inhalation habit) who survived for a longer period of follow up from the baseline examination than did the corresponding case.

The original spirograms of the cases and controls were retrieved from storage and the "best" of the three blows was chosen as the one with the highest sum of $\mathrm{FEV}_{1}$ and FVC. Flow rates were derived from this tracing by inspection between points when $20 \%, 50 \%, 60 \%$, $75 \%, 80 \%, 85 \%, 90 \%$, and $95 \%$ of FVC had been expired. These flow rates are designated as $\mathrm{FEF}_{20-50}, \mathrm{FEF}_{50-75}, \mathrm{FEF}_{20-75}, \mathrm{FEF}_{60-80}, \mathrm{FEF}_{75-}$ ${ }_{85}, \mathrm{FEF}_{80-90}$, and $\mathrm{FEF}_{85-95}$. In addition, $\mathrm{FEV}_{1}$, $\mathrm{FVC}$, and the $\mathrm{FEV}_{1} / \mathrm{FVC}$ ratio were examined as predictors of mortality from COPD. Throughout this paper we use the terms "mid expiratory flow rates" in a generic sense to refer to measures such as $\mathrm{FEF}_{20-50}, \mathrm{FEF}_{50-75}$, or $\mathrm{FEF}_{20-75}$, in contrast to flow rates later in the

Table 2 Mean (SD) spirometric indices from cases and controls

\begin{tabular}{llll}
\hline All pairs & Cases & Controls & Case:control ratio \\
\hline FEV $_{1}(1)$ & $1.83(0.67)$ & $2.67(0.74)$ & $0.66(0.62$ to 0.72$)$ \\
FVC $(1)_{F E V} / \mathrm{FVC}$ ratio & $2.98(0.79)$ & $3.52(0.76)$ & $0.82(0.78$ to 0.86$)$ \\
$\mathrm{FEF}_{20-75}(1 / \mathrm{s})$ & $0.61(0.13)$ & $0.75(0.10)$ & $0.81(0.78$ to 0.85$)$ \\
$\mathrm{FEF}_{20-50}(1 / \mathrm{s})$ & $1.18(0.69)$ & $2.55(1.22)$ & $0.45(0.40$ to 0.50$)$ \\
$\mathrm{FEF}_{50-75}(1 / \mathrm{s})$ & $2.07(1.24)$ & $4.08(1.90)$ & $0.47(0.41$ to 0.54$)$ \\
$\mathrm{FEF}_{60-80}(1 / \mathrm{s})$ & $0.80(0.51)$ & $1.85(1.02)$ & $0.43(0.38$ to 0.49$)$ \\
$\mathrm{FEF}_{75-85}(1 / \mathrm{s})$ & $0.58(0.37)$ & $1.29(0.77)$ & $0.46(0.41$ to 0.51$)$ \\
$\mathrm{FEF}_{80-90}(1 / \mathrm{s})$ & $0.36(0.21)$ & $0.69(0.45)$ & $0.55(0.50$ to 0.62$)$ \\
$\mathrm{FEF}_{85-95}(1 / \mathrm{s})$ & $0.26(0.11)$ & $0.42(0.25)$ & $0.66(0.60$ to 0.72$)$ \\
\hline
\end{tabular}

$\mathrm{FEV}_{1}=$ forced expiratory volume in one second $\mathrm{FVC}=$ forced vital capacity; FEF $=$ forced expiratory flow.

$\star$ Units are geometric mean ( $95 \%$ confidence interval). spirogram $\left(\mathrm{FEF}_{75-85}, \mathrm{FEF}_{80-90}\right.$, and $\left.\mathrm{FEF}_{85-95}\right)$ which we refer to as "end expiratory flow rates".

The cases and controls were analysed throughout as matched pairs. Certain analyses were conducted separately for deaths occurring less than 10 years, $10-14$ years, and 15 or more years after the baseline spirometric tests in order to evaluate the predictive power of each index for earlier and later death from COPD.

The emphasis in the presentation is on relative changes in spirometric indices because volumes and flow rates have different scales of measurement. Within pair contrasts between the case and control spirograms were expressed as the ratio of flow rates in cases compared with their matched controls. Matched pair relative risks of COPD mortality were derived from conditional logistic regression models fitted in Stata. ${ }^{13}$ Each spirometric index was modelled separately and then in combination with $\mathrm{FEV}_{1}$, with death from COPD as the dichotomous outcome variable. The results are expressed as the relative risk (mortality ratio) per 10\% reduction in each spirometric index relative to the mean value of the index in the control sample.

\section{Results}

Among 170 cases of fatal COPD 23 spirograms could not be traced: these corresponded to a specific range of identification numbers from a few missing storage boxes and are therefore unlikely to be a biased sample of all deaths. No control spirograms could be traced for a further four cases. Thus, matched case and control spirograms were found for 143 pairs ( $84 \%$ of 170 eligible deaths). These included 48 pairs where the case died within 10 years of baseline spirometric testing, 50 pairs where the case died 10-14 years after entry, and 45 pairs where the case died 15-19 years after baseline examination.

Table 1 shows the characteristics of the cases included in the study. Over half of them were aged 55-64 years when they performed the baseline spirometric tests. Most of the cases were aged 75-80 years when they died from COPD. Only $4 \%$ of the cases had never smoked. Chronic bronchitis was the most common certified cause of death in earlier years, but chronic airways obstruction became more commonly coded after 10 years of follow up, reflecting changing diagnostic conventions through the 1970s and 1980s.

Table 2 summarises the spirometric indices derived from case and control spirograms. The within pair comparisons are shown as geometric means for the case:control ratios and their coefficients of variation. Among all pairs, mid expiratory flow rates $\left(\mathrm{FEF}_{20-50}, \mathrm{FEF}_{50-75}\right.$, and $\mathrm{FEF}_{20-75}$ ) were reduced to a greater extent than end expiratory flow rates $\left(\mathrm{FEF}_{75-85}, \mathrm{FEF}_{80-90}\right.$, and $\mathrm{FEF}_{85-95}$ ). This pattern was evident among each of the three subgroups (deaths occurring $<10,10-14$, and 15-19 years after examination), although the differences between the case and control spirograms were more marked for earlier than for later deaths (not shown). 
Table 3 Mortality odds ratios and 95\% confidence intervals for COPD death, by survival interval, per 10\% decrease in each spirometric index (univariate models)

\begin{tabular}{lllll}
\hline & $\begin{array}{l}\text { Case survived <10 years } \\
(n=48)\end{array}$ & $\begin{array}{l}\text { Case survived 10-14 years } \\
(n=50)\end{array}$ & $\begin{array}{l}\text { Case survived 15-19 years } \\
(n=45)\end{array}$ & $\begin{array}{l}\text { All case-control pairs } \\
(n=143)\end{array}$ \\
\hline FVC & $2.61(1.45$ to 4.68$)$ & $1.70(1.23$ to 2.34$)$ & $1.95(1.24$ to 3.07$)$ & $1.97(1.55$ to 2.50$)$ \\
$\mathrm{FEV}_{1}$ & $4.65(1.48$ to 14.6$)$ & $2.12(1.36$ to 3.30$)$ & $1.61(1.21$ to 2.15$)$ & $2.06(1.61$ to 2.63$)$ \\
$\mathrm{FEV}_{1} / \mathrm{FVC}$ & $1.97(1.35$ to 2.88$)$ & $4.77(1.97$ to 11.5$)$ & $2.02(1.33$ to 3.08$)$ & $2.36(1.79$ to 3.11$)$ \\
$\mathrm{FEF}_{20-50}$ & $2.32(1.28$ to 4.20$)$ & $1.83(1.28$ to 2.60$)$ & $1.30(1.11$ to 1.52$)$ & $1.55(1.35$ to 1.79$)$ \\
$\mathrm{FEF}_{50-75}$ & $2.52(1.34$ to 4.72$)$ & $1.96(1.26$ to 3.04$)$ & $1.76(1.25$ to 2.48$)$ & $1.98(1.54$ to 2.54$)$ \\
$\mathrm{FEF}_{20-75}$ & $2.86(1.36$ to 6.03$)$ & $2.66(1.31$ to 5.41$)$ & $1.50(1.19$ to 1.90$)$ & $1.90(1.52$ to 2.38$)$ \\
$\mathrm{FEF}_{60-80}$ & $2.57(1.39$ to 4.78$)$ & $1.63(1.20$ to 2.21$)$ & $1.97(1.32$ to 2.95$)$ & $1.93(1.53$ to 2.46$)$ \\
$\mathrm{FEF}_{75-85}$ & $1.93(1.27$ to 2.92$)$ & $1.50(1.18$ to 1.91$)$ & $1.41(1.14$ to 1.75$)$ & $1.54(1.32$ to 1.79$)$ \\
$\mathrm{FEF}_{80-90}$ & $1.42(1.12$ to 1.79$)$ & $1.47(1.17$ to 1.85$)$ & $1.64(1.20$ to 2.24$)$ & $1.50(1.29$ to 1.74$)$ \\
$\mathrm{FEF}_{85-95}$ & $1.57(1.18$ to 2.10$)$ & $1.23(1.05$ to 1.44$)$ & $1.22(0.98$ to 1.51$)$ & $1.31(1.16$ to 1.47$)$ \\
\hline
\end{tabular}

For abbreviations see footnote to table 2 .

Table 4 Correlations of within pair case compared to smoking control ratios of each spirometric index

\begin{tabular}{|c|c|c|c|c|c|c|c|c|}
\hline & \multicolumn{8}{|c|}{ Correlations $^{*}$ of within pair case:control ratios of each spirometric index } \\
\hline & FVC & $F E V_{1}$ & $F E F_{20-75}$ & $F E F_{20-50}$ & $\mathrm{FEF}_{50-75}$ & $F E F_{60-80}$ & $F E F_{75-85}$ & $F E F_{80-90}$ \\
\hline $\mathrm{FEV}_{1}$ & 0.87 & - & & & & & & \\
\hline $\mathrm{FEF}_{20-75}$ & 0.73 & 0.92 & - & & & & & \\
\hline $\mathrm{FEF}_{20-50}$ & 0.69 & 0.89 & 0.91 & - & & & & \\
\hline $\mathrm{FEF}_{50-75}$ & 0.70 & 0.87 & 0.97 & 0.80 & - & & & \\
\hline $\mathrm{FEF}_{60-80}$ & 0.69 & 0.83 & 0.92 & 0.72 & 0.97 & - & & \\
\hline $\mathrm{FEF}_{75-85}$ & 0.66 & 0.73 & 0.79 & 0.60 & 0.84 & 0.92 & - & \\
\hline $\mathrm{FEF}_{80-90}^{75-85}$ & 0.60 & 0.64 & 0.67 & 0.48 & 0.73 & 0.83 & 0.93 & - \\
\hline $\mathrm{FEF}_{85-95}^{80-90}$ & 0.44 & 0.39 & 0.38 & 0.20 & 0.46 & 0.57 & 0.66 & 0.81 \\
\hline
\end{tabular}

For abbreviations see footnote to table 2. ${ }^{\star}$ Pearson correlation coefficients derived from log transformed ratios.

Table 3 shows the mortality ratios derived from univariate conditional logistic regression models for all pairs and for subgroups defined by survival interval. Overall, a $10 \%$ reduction in $\mathrm{FEV}_{1}, \mathrm{FVC}, \mathrm{FEV}_{1} / \mathrm{FVC}$ ratio, $\mathrm{FEF}_{20-75}$, $\mathrm{FEF}_{50-75}$, or $\mathrm{FEF}_{60-80}$ was associated with an approximate doubling of the risk of death from COPD, whereas the association was weaker with end expiratory flow rates $\left(\mathrm{FEF}_{75-85}\right.$, $\mathrm{FEF}_{80-90}$, and $\left.\mathrm{FEF}_{85-95}\right)$. The mortality ratios

Table 5 Mortality odds ratios and 95\% confidence intervals for COPD death in all case:control pairs, per $10 \%$ decrease in each spirometric index, before and after adjustment for $\mathrm{FEV} V_{1}$

\begin{tabular}{llll}
\hline & $\begin{array}{l}\text { Effect of spirometric index } \\
\text { before adjustment } \\
\text { (univariate model) }\end{array}$ & $\begin{array}{l}\text { Effect of spirometric index } \\
\text { adjusted for } F E V_{1} \\
\text { (bivariate model) }\end{array}$ & $\begin{array}{l}\text { Effect of FEV } V_{1} \text { adjusted } \\
\text { for the index } \\
\text { (bivariate model) }\end{array}$ \\
\hline $\mathrm{FEV}_{1}$ & $2.06(1.61$ to 2.63$)$ & - & $2.06(1.61$ to 2.63$)$ \\
$\mathrm{FEV}_{1} / \mathrm{FVC}$ & $2.36(1.79$ to 3.11$)$ & $1.22(0.90$ to 1.64$)$ & $1.86(1.40$ to 2.48$)$ \\
$\mathrm{FEF}_{20-50}$ & $1.55(1.35$ to 1.79$)$ & $1.24(1.01$ to 1.53$)$ & $1.53(1.08$ to 2.18$)$ \\
$\mathrm{FEF}_{50-75}$ & $1.98(1.54$ to 2.54$)$ & $2.24(1.45$ to 3.47$)$ & $0.86(0.57$ to 1.30$)$ \\
$\mathrm{FEF}_{20-75}$ & $1.90(1.52$ to 2.38$)$ & $2.40(1.54$ to 3.76$)$ & $0.73(0.46$ to 1.17$)$ \\
$\mathrm{FEF}_{60-80}$ & $1.93(1.53$ to 2.46$)$ & $1.75(1.26$ to 2.42$)$ & $1.15(1.22$ to 1.63$)$ \\
$\mathrm{FEF}_{75-85}$ & $1.54(1.32$ to 1.79$)$ & $1.20(1.00$ to 1.42$)$ & $1.73(1.33$ to 2.26$)$ \\
$\mathrm{FEF}_{80-90}$ & $1.50(1.29$ to 1.74$)$ & $1.19(1.00$ to 1.41$)$ & $1.82(1.43$ to 2.34$)$ \\
$\mathrm{FEF}_{85-95}$ & $1.31(1.16$ to 1.47$)$ & $1.10(0.96$ to 1.26$)$ & $1.99(1.55$ to 2.56$)$ \\
\hline
\end{tabular}

For abbreviations, see footnote to table 2 .

^From table 3 .

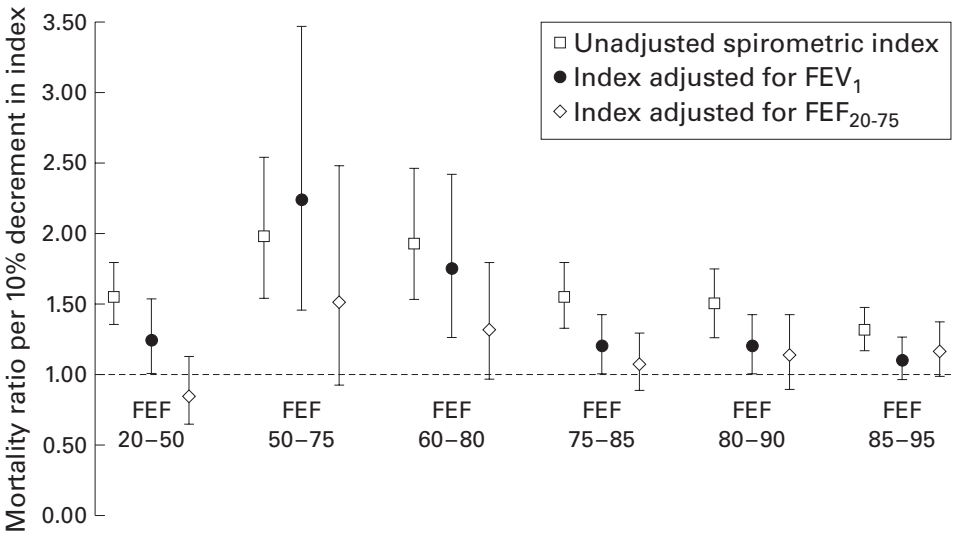

Figure 1 Mortality ratios for unadjusted and adjusted spirometric indices. were generally greater for earlier than for later deaths and, among end expiratory flow rates, only $\mathrm{FEF}_{80-90}$ was more strongly associated with later deaths.

The within pair case: control ratios for most indices were highly correlated (table 4 ). In particular, the case:control ratio of $\mathrm{FEV}_{1}$ (the most widely used index in other studies) was closely related to ratios of all other indices except FEF $_{85-95}$.

Table 5 shows the effect of including $\mathrm{FEV}_{1}$ as a covariate in the regression models. Adjustment for $\mathrm{FEV}_{1}$ substantially weakened the association of COPD mortality with $\mathrm{FEV}_{1}$ / FVC ratio, $\mathrm{FEF}_{75-85}, \mathrm{FEF}_{80-90}$, and $\mathrm{FEF}_{85-95}$, and in these models the coefficient for $\mathrm{FEV}_{1}$ was similar to that obtained by univariate analysis - that is, a doubling of risk per $10 \%$ decrease in $\mathrm{FEV}_{1}$. In contrast, when $\mathrm{FEF}_{20-75}$ and $\mathrm{FEV}_{1}$ were modelled jointly, the effect of $\mathrm{FEV}_{1}$ was nullified and the mortality risk remained closely associated with $\mathrm{FEF}_{20-75}$. Similar patterns were observed for $\mathrm{FEF}_{50-75}$ and $\mathrm{FEF}_{60-80}$.

Figure 1 shows the effect of each spirometric index on COPD mortality before and after adjustment, in turn, for $\mathrm{FEV}_{1}$ and $\mathrm{FEF}_{20-75}$. None of the other indices was strongly or significantly related to death from COPD after adjustment for $\mathrm{FEF}_{20-75}$, whereas the approximate doubling in the mortality risk associated with a $10 \%$ decrease in mid expiratory flow rate was sustained after adjustment for each of the other variables. There was no evidence of a substantial or significant independent effect of end expiratory flow rates on COPD mortality even in the subgroup where the case died 15 or more years after spirometric testing-for example, the odds ratio for a $10 \%$ decrement in $\mathrm{FEF}_{75-85}$ adjusted for $\mathrm{FEF}_{20-75}$ was 1.15 (95\% CI 0.92 to 1.44 ) for this later group of deaths. 


\section{Discussion}

It is well known that lung function is a predictor of mortality from COPD, and the most commonly used clinical measurement is the age and height adjusted $\mathrm{FEV}_{1}$. Our study design controlled for age and height by matching. Cases and controls were also matched for smoking habit because it was anticipated that lifetime smoking might influence risk of death, independent of lung function, and differentially affect early, mid, and end expiratory flow rates. For instance, a relatively greater reduction in end expiratory flow rates than $\mathrm{FEV}_{1}$ in current smokers may reflect inflammatory changes in the smaller airways ${ }^{14}$ causing structural narrowing and associated airflow limitation. ${ }^{15}$

This is the first epidemiological study to evaluate flow rates from different parts of the forced expiratory spirogram as predictors of mortality from COPD. The results suggest that mid expiratory, rather than end expiratory, flow rates are the most consistent and independent predictors of subsequent death from COPD, even 15 or more years after measurement. The most widely used index, $\mathrm{FEV}_{1}$, is closely related to mid expiratory flow rates and is likely to remain the predictor of choice for epidemiological studies. There was no evidence that end expiratory flow rates measured in late middle age were independently related to later COPD mortality, typically after age 70 years. We were unable to evaluate predictors of earlier deaths.

However, in this case-control sample, within pair ratios of $\mathrm{FEF}_{75-85}$ were closely correlated with within pair ratios of mid expiratory flow rates and both were highly correlated with within pair ratios of $\mathrm{FEV}_{1}$. This may have led to misleading results when these indices were included together in the multivariate regression models. Colinearity is less of a problem for $\mathrm{FEF}_{85-95}$ but, in this terminal part of the spirogram, measurement error may have diluted both the correlations with other spirometric indices and the associations with fatal COPD.

A further limitation of the study is the restriction to 20 years of follow up. If the smaller airways are affected early in the natural history of COPD, their function should ideally be studied 30 or 40 years before death. This ideal remains unattainable at present because spirometry did not become widely used in epidemiological studies until the $1960 \mathrm{~s},{ }^{1}$ and the Whitehall study was one of the largest prospective studies from this early period. Unfortunately, the spirograms from the remainder of the cohort were destroyed in 1990 so the opportunity for more prolonged follow up on this cohort does not arise.

In conclusion, this study confirms the validity of $\mathrm{FEV}_{1}$ as a powerful predictor of mortality from COPD and suggests that measurement of end expiratory flow rates would add little extra predictive information.

We are grateful to the late Geoffrey Rose who allowed the spirograms to be selected and preserved for later analysis. Data preparation from the spirograms and statistical analysis were supported in part by funding from $3 \mathrm{M}$ Health Care Limited.

1 Peto R, Speizer FE, Cochrane AL, et al. The relevance in adults of airflow obstruction, but not of mucus hypersecretion, to mortality from chronic lung disease. Am Rev Respir Dis 1983;128:491-500.

2 Annesi I, Kauffmann F. Is respiratory mucus hypersecretion really an innocent disorder? Am Rev Respir Dis 1986;134: 688-93.

3 Lange P, Nyboe J, Appleyard M, et al. The relation of ventilatory function impairment and of chronic mucus hypersecretion to mortality from obstructive lung disease and from all causes. Thorax 1990;45:579-85.

4 Ebi-Kryston KL. Predicting 15-year chronic bronchitis mortality in the Whitehall study. F Epidemiol Community Health 1989;43:168-72.

5 Hogg JC, Macklem PT, Thurlbeck WM. Site and nature of airway obstruction in chronic obstructive lung disease. $N$ airway obstruction in chronic
Engl $₹$ Med $1968 ; 268: 1355-60$.

6 Macklem PT. Obstruction in the small airways. $\mathrm{Am} 7 \mathrm{Med}$ 1972;52:721-4

7 Soloman D. Clinical significance of pulmonary function tests: are small airways tests helpful in the detection of early airflow obstruction? Chest 1978;74:567-9.

8 Evans DJ, Green M. Small airways: a time to revisit? Thorax 1998;52:629-30

9 Reid DD, Brett GZ, Hamilton PJS, et al. Cardiorespiratory servants. A study of among middle-aged male civil 1974;i:469-72.

10 Ebi-Kryston KL. Respiratory symptoms and pulmonary function as predictors of 10-year mortality from respiratory disease, cardiovascular disease and all causes in the Whitehall study. F Epidemiol Community Health 1988;41:251-60.

11 hall study. F Epidemiol Community Health $1988 ; 41: 251-60$. stroke. BMF 1991;302:84-7.

12 Strachan DP. Ventilatory function, height and mortality among lifelong non-smokers. 7 Epidemiol Community Health 1990,; 46:66-70.

13 Stata Corporation. STATA Statistical Software: release 5.0. College Station, Texas: Stata Corporation, 1997.

14 Wright JL, Hobson J, Wiggs BR, et al. Effect of cigarette smoking on structure of the small airways. Lung 1987;165: 91-100.

15 Greaves IA, Colebatch HJ. Observations on the pathogenesis of chronic airflow obstruction in smokers: implications $81-7$ 